\title{
Plot and field scale soil moisture dynamics and subsurface wetness control on runoff generation in a headwater in the Ore Mountains
}

\author{
E. Zehe ${ }^{1}$, T. Graeff ${ }^{2}$, M. Morgner ${ }^{1}$, A. Bauer ${ }^{2}$, and A. Bronstert ${ }^{2}$ \\ ${ }^{1}$ Institute for Water and Environment, Department of Hydrology and River Basin Management, Technische Universität \\ München, Germany \\ ${ }^{2}$ Institute for Geoecology, Section of Hydrology/Climatology, University of Potsdam, Germany
}

Received: 1 December 2009 - Published in Hydrol. Earth Syst. Sci. Discuss.: 16 December 2009

Revised: 26 April 2010 - Accepted: 19 May 2010 - Published: 1 June 2010

\begin{abstract}
This study presents an application of an innovative sampling strategy to assess soil moisture dynamics in a headwater of the Weißeritz in the German eastern Ore Mountains. A grassland site and a forested site were instrumented with two Spatial TDR clusters (STDR) that consist of 39 and 32 coated TDR probes of $60 \mathrm{~cm}$ length. Distributed time series of vertically averaged soil moisture data from both sites/ensembles were analyzed by statistical and geostatistical methods. Spatial variability and the spatial mean at the forested site were larger than at the grassland site. Furthermore, clustering of TDR probes in combination with long-term monitoring allowed identification of average spatial covariance structures at the small field scale for different wetness states. The correlation length of soil water content as well as the sill to nugget ratio at the grassland site increased with increasing average wetness and but, in contrast, were constant at the forested site. As soil properties at both the forested and grassland sites are extremely variable, this suggests that the correlation structure at the forested site is dominated by the pattern of throughfall and interception. We also found a very strong correlation between antecedent soil moisture at the forested site and runoff coefficients of rainfall-runoff events observed at gauge Rehefeld. Antecedent soil moisture at the forest site explains $92 \%$ of the variability in the runoff coefficients. By combining these results with a recession analysis we derived a first conceptual model of the dominant runoff mechanisms operating in this catchment. Finally, we employed a physically based hydrological model to shed light on the controls of soil- and plant morphological parameters on soil average soil mois-
\end{abstract}

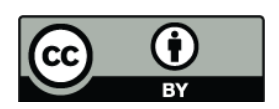

Correspondence to: E. Zehe (e.zehe@bv.tum.de) ture at the forested site and the grassland site, respectively. A homogeneous soil setup allowed, after fine tuning of plant morphological parameters, most of the time unbiased predictions of the observed average soil conditions observed at both field sites. We conclude that the proposed sampling strategy of clustering TDR probes is suitable to assess unbiased average soil moisture dynamics in critical functional units, in this case the forested site, which is a much better predictor for event scale runoff formation than pre-event discharge. Long term monitoring of such critical landscape elements could maybe yield valuable information for flood warning in headwaters. We thus think that STDR provides a good intersect of the advantages of permanent sampling and spatially highly resolved soil moisture sampling using mobile rods.

\section{Introduction}

Soil moisture is a key state variable that controls hydrological dynamics at various spatial scales. There is experimental evidence that the onset of point scale threshold processes such as fast preferential flow in soil (Blume et al., 2009; Zehe and Flühler, 2001), Hortonian overland flow initiation (Zehe et al., 2007), or the switch between hydrophilic and hydrophobic conditions are strongly controlled by antecedent soil moisture conditions (Dekker et al., 2005). Furthermore, various studies suggest that the antecedent soil moisture state exerts crucial control on rainfall-runoff response at the field and headwater scale (Bronstert and Bárdossy, 1999; Meyles et al., 2003; Montgomery and Dietrich, 2002; Jayawardena and Zhou, 2000; Gurtz et al., 1999; Chirico et al., 2003; Zehe and Blöschl, 2004; Zehe et al., 2005, Blöschl and Zehe, 2005 ) or on the preferred flow regime in small catchments

Published by Copernicus Publications on behalf of the European Geosciences Union. 
(Grayson et al., 1997). However, most of the listed studies rely to a large degree on modelling. Experimental studies that relate observations of spatio-temporal soil moisture dynamics at the field or headwater scale to observed flows, either at the surface or in the stream, are rare (Burt and Butcher, 1985, Grayson et al., 1997; Starr and Timlin, 2004; McNamara et al., 2005; Lin, 2006; Frisbee et al., 2007). Notwithstanding that they could offer additional - probably unexpected - pieces of information to the puzzle that up to now has largely comprised model extrapolations. The reason for the limited number of field studies is well known. Soil moisture at the headwater scale exhibits huge spatial variability and single or even distributed TDR measurements yield nonrepresentative data.

Promising technologies to assess spatially distributed three-dimensional soil moisture proxies at the field scale are ground penetrating radar (GPR) (Binley et al., 2002; Roth et al., 2004) or electrical resistivity soundings (ERT) (e.g. Graeff et al., 2009; Kemna et al., 2002). The former yields the subsurface pattern of the dielectric permittivity, the latter the subsurface pattern of the apparent specific resistivity. The difficulty for both methods is that there are no general petro-physical relationships available to transform the observed variables into soil water content (Paasche et al., 2006). A draw-back of both methods is that observations are - in most cases - restricted to field campaigns and therefore provide only a coarse temporal resolution.

Most past and recent studies have largely relied on distributed TDR observations. One approach is to use a set of fixed TDR sensors to monitor temporal soil moisture dynamics at selected points as for instance suggested by Bárdossy and Lehmann (1995) in the Weiherbach, Germany, Anctil et al. (2008) in the Orgeval watershed, France or Blume et al. $(2009,2008 \mathrm{a}, \mathrm{b})$ in the Mallacahuelo catchment in Chile. The advantage of using fixed stations is that they allow a high temporal resolution, which allows either comparison of observed point soil moisture dynamics to event scale discharge response and piezometers response as suggested by Blume et al. (2008a), or to use this information to improve discharge predictions as recently shown by Anctil et al. (2008). The drawback of this approach is that we cannot achieve a high spatial resolution with this approach, simply because of the high costs. Other authors prefer thus spatially highly resolved soil moisture sampling by means of mobile or portable TDR sensors, as for instance Grayson et al. (1997) or Grayson and Western (1998) in the Tarawarra, Chickasha and Lockerysleigh catchments in Australia or Brocca et al. $(2007,2009)$ for three field sites in the upper Tiber valley. Spatially distributed sampling allows identification temporal changes in correlation structure and spatial variability depending on the average near surface wetness. Albertson and Montaldo (2003) and Western et al. (2004) found for instance a reduction in variance and an increasing correlation length with increasing wetness of a field sites in Australia. Similar Brocca et al. (2007) report at their rather homogeneous site that soil moisture variance reduced during wet conditions and soil moisture was normally distributed in the flat valleys areas. Brocca et al. (2007) and Grayson and Western (1998) defined furthermore representative sites whose soil moisture values are always close to the overall average. Brocca et al. (2009) found further that the ranks of their distributed measurements in the univariate soil moisture distribution at a fixed time did not change much between different observation times. This temporal stability of the ranks suggests that the moisture pattern reflects the pattern of stationary soil properties, at least at the seasonal scale. Blume et al. (2008a, b) found, however, at a much more heterogeneous and forested site, partly contradicting results. The main drawback of using mobile TDR sensors is the limited temporal resolution that is too coarse for relating observed soil moisture dynamics to systems behaviour under rainfall driven conditions.

In this study we suggest another approach to assess representative soil moisture data for typical landscape units in a headwater catchment in the Ore Mountains and to explore subsurface wetness control on runoff generation. The idea is to combine advanced spatial TDR technology (Schlaeger, 2005; Becker, 2004; Graeff et al., 2010) that allows even retrieval of soil moisture data with an innovative sampling strategy, that combines the advantage of both approaches discussed above. Before we further elaborate on this sampling strategy we think is helpful to precisely define what we mean with "soil moisture variability" and what determines a "soil moisture ensemble" in a statistical sense. Spatio-temporal variability of soil moisture is determined by a multitude of spatial patterns that interact in a nonlinear way in space and time. During and after extreme precipitation events we expect the spatial rainfall pattern to be dominant. Hence, soil moisture is expected to be spatially uniform (Grayson et al., 1997; Grayson and Western, 1998; Brocca et al., 2007). With increasing dryness, terrain, soil types and vegetation begin to dominate more and more and soil moisture variability is expected to increase as shown by Brocca et al. (2007), Grayson et al. (1997), Grayson and Western (1998) or Western et al. (2004). We, thus, suggest that a "soil moisture ensemble" is defined as an area that is uniform with respect to soil type, terrain properties and vegetation class (Wilson et al., 2004), but also rainfall and radiation forcing. We expect at least that the first moment of the soil moisture pattern the mean - should be constrained by soil type, vegetation and terrain. Understanding this deterministic part of spatial soil moisture variability requires therefore that we determine "representative mean values" within different ensembles or strata. In "heterogeneous systems" this is, however, highly complicated by local scale statistical soil moisture variability within such an ensemble that stems from local fluctuations of soil hydraulic properties, macropores and micro topography. For instance, Zehe and Blöschl (2004) found the variance of soil water content observed within a cluster of 25 TDR measurements at a $4 \mathrm{~m}^{2}$ large field plot was with 
$0.04\left(\mathrm{~m}^{3} \mathrm{~m}^{-3}\right)^{2}$ as large as the soil moisture variance observed at 61 locations in the $3.2 \mathrm{~km}$ large Weiherbach catchment. However, they showed furthermore that the first two moments observed within a different cluster of 25 TDR measurements at a different plot were within the confidence limits identical to those obtained at the plot. Similarly Brocca et al. (2007) found that 9 to 35 measurements allow assessment of a stable mean soil moisture values.

We therefore suggest that clustering of several TDR probes within different ensembles/strata seems a promising strategy to discriminate different sources of soil moisture variability (deterministic and stochastic) and combine the advantages high temporal and locally high spatial resolution. A set of fixed TDR stations equally distributed in a catchment would mix these sources of variability because it will cover several ensembles. As long as the total spatial extent of the network is small enough to neglect spatial variability of rainfall and radiation, both sources of variability may still be unrevealed using appropriate geostatistical methods and a stratified sampling (Bárdossy and Lehmann, 1998; Zehe et al., 2005). However, the sampling size in the individual classes may become too small to allow representative estimates of prior distributions, even when up to 100 TDR stations are installed, as reported in the study of Bárdossy and Lehmann (1998). A TDR cluster may be furthermore operated at a sampling interval of $10 \mathrm{~min}$ for up to 40 sensors and may cover an area of up to $500 \mathrm{~m}^{2}$. This can be deemed as sufficient to investigate soil moisture control on runoff generation and to shed light on a possible dependence of field scale soil moisture variance on the average wetness state or on the spatial pattern of soil moisture changes under different conditions. The ideal case is that the individual TDR probes within such a cluster yield soil moisture profiles instead of an integral value along the probe. This would allow assessment of highly resolved infiltration data to test and improve the current generation of soil hydrological models for flow in the unsaturated zone (compare Graeff et al., 2010). The drawback of the operating STDR clusters is, however, that a single one costs roughly $12-15 \mathrm{~K} €$.

This study presents an application of the outlined STDR technology (the underlying theory is well explained in Graeff et al. (2010), in a headwater of the Weißeritz in the German eastern Ore Mountains, where two TDR clusters have been installed since summer 2007. In principle, one may obtain two types of soil moisture data from these clusters: (1) the usual vertically averaged soil moisture values at the individual probes based on the travel time of the TDR signal we use here, and (2) inverted soil moisture profiles based on the approach suggested by Schlaeger (2005), as explained in Graeff et al. (2010). Identification of reliable soil moisture profiles in these soils was, however, complicated by unexpected error sources such as very strong probe deformations, strong vertical gradients in porosity and density, and the presence of gravel and stones in the integration volume, which all arose when installing the TDR probes in these highly hetero- geneous soils. Graeff et al. (2010) reports in detail how these error sources affect retrieval of soil moisture profiles in these soils. They found that the vertically averaged soil moisture is not affected by these errors but inverted soil moisture profiles may be strongly biased. The main objective of the present study is thus to:

- Investigate how different ensembles determine the mean, variance and correlation length (range) of vertically averaged soil moisture values and whether the variance and range depends on the average wetness within the ensemble,

- To explore the relationship between spatial average soil moisture dynamics obtained within one TDR cluster and the discharge response at the outlet of the $16 \mathrm{~km}^{2}$ large catchment,

- To compare observations with long-term simulations with of physically based hydrological model CATFLOW to investigate soil and vegetation controls on observed soil moisture dynamics and explore whether the spatial extend of the STDR clusters allows indeed assessment of a representative mean soil moisture dynamics.

\section{Study area and field instrumentation}

The study area is a headwater of the Weißeritz River close to the village of Rehefeld. The Weißeritz basin is located in the eastern part of the Ore Mountains, East Germany, between $50^{\circ} 40^{\prime}$ and $50^{\circ} 49^{\prime}$ northern latitude and $13^{\circ} 35^{\prime}$ and $13^{\circ} 45^{\prime}$ eastern longitude. It consists of two main channels, the Red and Wild Weißeritz, which jointly contribute to the Elbe River at the city of Dresden. The basin covers an area of $384 \mathrm{~km}^{2}$ and stretches over $15 \mathrm{~km}$ from north to south, with an average elevation of approximately $730 \mathrm{~m}$ reaching from $910 \mathrm{~m}$ at Pramenac to $527 \mathrm{~m}$ at its outlet. About $60 \%$ of the basin is dominated by spruce stands, deciduous species and mixed type of forests; some $20 \%$ grassland, $10 \%$ arable land, $4 \%$ swamps and $6 \%$ settlements characterize the remaining parts of the catchment. Annual rainfall is approximately $950-1050 \mathrm{~mm}$ and average annual temperature is between $4-5.5^{\circ} \mathrm{C}$.

In summer 2006, the Rehefeld headwater was selected as a study area for the BMBF-funded OPAQUE project. The drainage area is approximately $16 \mathrm{~km}^{2}$. Soils of the eastern Ore Mountains formed as weathered cover during the Weichsel cold age. Apparent soils are loamy Campisols, their depth, texture and gravel content is highly variable in space. Land use is dominated by forest and pasture. For more than 20 years water levels have been observed at the Rehefeld river gauge operated by the Federal State of Saxony (Landestalsperrenverwaltung Sachsen). The headwater was additionally instrumented with six rain gauges, a meteorological 

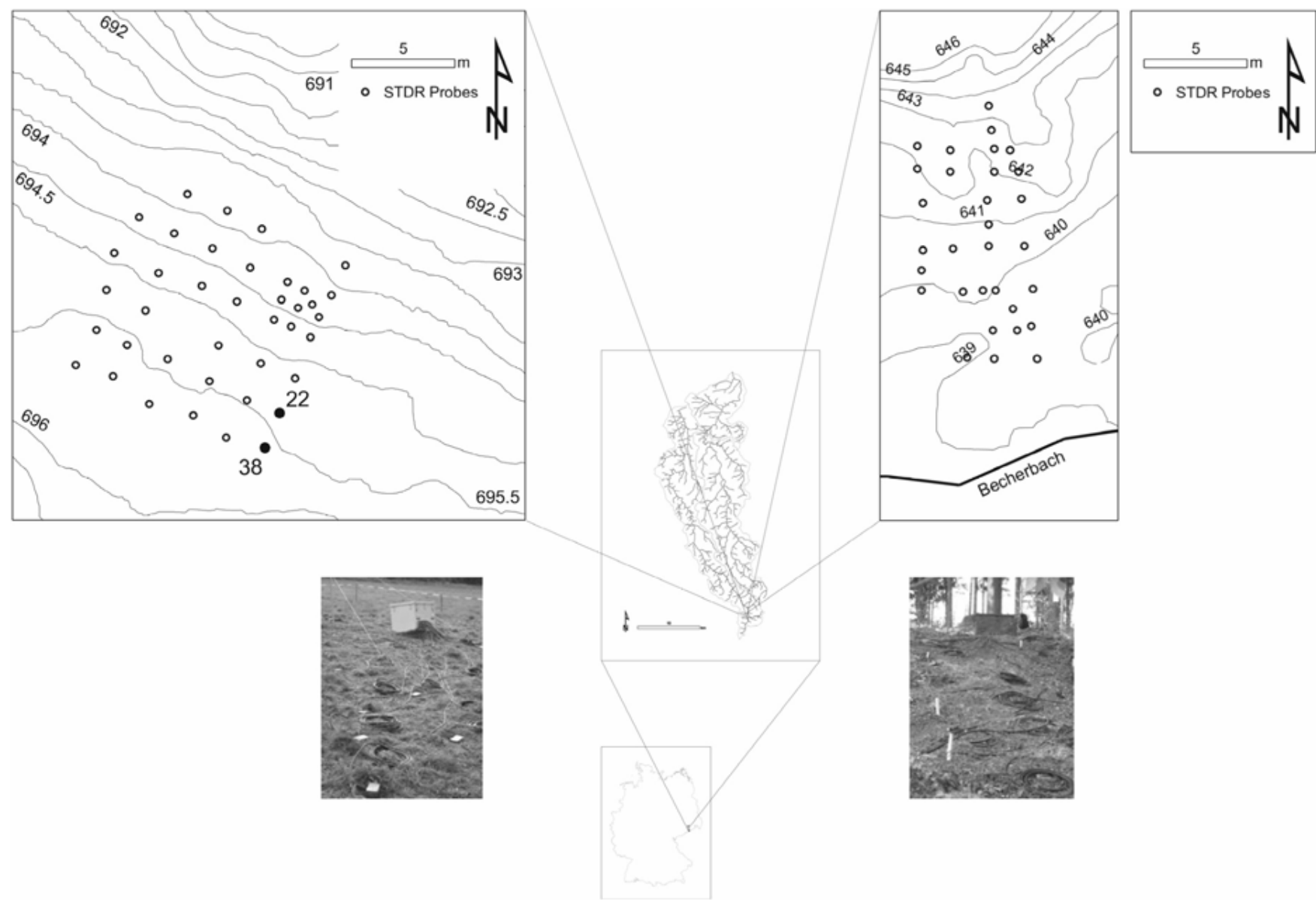

Fig. 1. Map view of the Rehefeld headwater with instrumentation, spatial arrangement of TDR probes in Clusters C1 and C2 as well as photos to highlight the differences between the two sites of $\mathrm{C} 1$ (left) and C2 (right).

station, several "TruTracks" (Intech Instruments LTD.) to observe shallow groundwater and two STDR clusters.

Cluster $\mathrm{C} 1$ is installed in open grassland and consists of 39 TDR probes (Fig. 1). Cluster C2 has been installed at a forested site and consists of 31 sensors. The TDR sensors we use are $60 \mathrm{~cm}$ long insulated three-rod probes of type SUSU03 (Schädel, 2006), which are connected via $15 \mathrm{~m}$ coaxial cables and a multiplexer to a TDR100 (Campbell Scientific Inc.). The probes are connected to a TDR100 (Campbell Scientific Inc.) via an eight channel multiplexer of type SNAPMUX (Becker, 2004) by means of coaxial cables of type RG213 with an impedance of $50 \Omega$ and a length $15 \mathrm{~m}$. The TDR 100 is controlled by ARCOM VIPER 1.2 Industrial-PC with embedded LINUX operating system that also serves as data logger. A combination of a HS-L 130 solar panel (Siemens) with a power rating of $130 \mathrm{~W}$ and a $12 \mathrm{~V}$ gel battery guided by a solar controller SLR 2016 provides an independent power supply in the field even under winter conditions. Data collection of soil moisture data started in May 2007 at a sampling interval of $1 \mathrm{~h}$. Installation of the $60 \mathrm{~cm}$ long STDR probes at both sites was a challenge, mainly due to the large amount of gravel as well as high soil stability. Even when using a steel template with three holes at the right distance and an electric drill, on average about two attempts were necessary to drill three holes down to a sufficient depth. Soil profiles that were excavated to check for proper installation showed that TDR probes were often deformed. Probe deformations affect the capacitance of the transmission line and this is crucial in the context of TDR inversion (Schlaeger, 2005; Becker, 2004). In a laboratory study Graeff et al. (2010) showed that probe deformations have a minor influence on TDR travel times and therefore on the vertically averaged soil water content. However, retrieved soil moisture profiles can be seriously corrupted by rod deformations.

The soil at the grassland site of $\mathrm{C} 1$ is a clay loam (Table 1). The upper $20 \mathrm{~cm}$ exhibit a high content of organic matter which is reflected in the low bulk density of $1 \mathrm{~g} / \mathrm{cm}^{3}$ and very large porosity of 0.63 . Soil stability is nonetheless high due to the large amount of gravel and aggregated material. Consequently, soil hydraulic conductivity in the top is large, around $4 \times 10^{-5} \mathrm{~m} / \mathrm{s}$, and decreases by one order of 
Table 1. Average soil properties obtained at grassland site $\mathrm{C} 1, \rho$, is the bulk density, $k_{\mathrm{S}}$ is saturated hydraulic conductivity.

\begin{tabular}{ccccccc}
\hline Depth $(\mathrm{cm})$ & Sand $(\%)$ & Silt $(\%)$ & Clay $(\%)$ & $k_{\mathrm{S}}(\mathrm{m} / \mathrm{s})$ & $\rho\left(\mathrm{g} / \mathrm{cm}^{3}\right)$ & Porosity (-) \\
\hline 10.0 & 38.0 & 34.5 & 27.5 & $4.16 \times 10^{-5}$ & $0.98 \pm 0.08$ & $0.63 \pm 0.05$ \\
30.0 & 29.0 & 50.6 & 20.4 & $1.58 \times 10^{-6}$ & $1.03 \pm 0.08$ & $0.61 \pm 0.04$ \\
50.0 & 27.0 & 51.6 & 21.4 & $4.14 \times 10^{-6}$ & $1.04 \pm 0.08$ & $0.61 \pm 0.04$ \\
\hline
\end{tabular}

magnitude in $30 \mathrm{~cm}$ depth. Surface infiltrability measured with a constant head infiltrometer was at around $10^{-4} \mathrm{~m} / \mathrm{s}$. The soil at the forested site of $\mathrm{C} 2$ has even higher infiltrability - beyond the measurement range - which is explained by the lower bulk density and higher organic content of the top soil (Table 2). At both sites gravel content increases with increasing depth. In their laboratory study Graeff et al. (2010) showed furthermore that gravel within the integration volume has a minor influence both on TDR travel times (and thus average soil moisture) as well as on retrieved soil moisture profiles.

\section{Data analyses and modelling}

\subsection{TDR travel times, depth integrated soil water con- tent and outliers}

Within this study we will focus on data observed in the period between 3 May 2007 and 26 October 2007, which is the frost-free period in 2007. TDR travel times were determined by detecting the time of steepest ascent in the first (signal entry) and second main reflection (reflection at the open end of the probe) in the reflectogram (Becker, 2004). Although there was a large amount of data gathered within an automated procedure, reflectograms of each individual probe were visually inspected frequently for their quality. Based on the calculated average dielectric permittivity, the average soil water content was calculated after Herkelrath et al. (1991; compare Graeff et al., 2010). The data underlying this study are hence time series of vertically averaged soil water contents obtained within the two clusters and the related time series of temporal soil moisture changes.

\subsection{Statistical and geostatistical analysis}

First, both types of time series were cleaned from outliers that were defined as values that drop outside the $99.9 \%$ range observed at an individual probe. Next, time series of the spatial mean and standard deviation, both of the soil moisture values and the hourly soil moisture changes, were computed. Times where the number TDR probes with measurements dropped below 10 were excluded from this procedure.

The spatial covariance structure of vertically integrated soil water content was analyzed within two steps. First we calculated the temporal means and standard deviations for the individual TDR probes in a cluster, simply to reduce noise that is introduced by small-scale variability in surface and subsurface water flow during individual events. Based on these values, we selected dry and wet days where the individual soil moisture values at the TDR probes differed more than plus/minus the standard deviation from the mean and then averaged these values in time to assess average conditions during dry and wet conditions for the individual probes. The resulting values reflect the average spatial distribution of soil water contents during average, wet and dry conditions. In a second step we calculated experimental variograms using the Matheron estimator and fitted a spherical variogram function by minimizing least squared differences. Minimum lag was 1.1 times the minimum probe distance; lag tolerance as set to $50 \%$. Lag classes with less than 30 pairs were not included in the fit. As necessary conditions for second-order stationarity, we checked whether the residuals were Gaussian distributed with zero mean. This was fulfilled in all cases. Due to the small extent of a STDR cluster, geostatistical analysis is somewhat limited as the maximum detectable range corresponds roughly to $50 \%$ of the maximum lag. The maximum lag distance is $15 \mathrm{~m}$.

\subsection{Subsurface wetness and soil moisture control on runoff generation}

In a first assessment we computed the Pearson correlation coefficient between the spatial average soil moisture at the grassland cluster $\mathrm{C} 1$ and catchment discharge. During the observation period we recorded in total nine rainfall runoff events (compare Fig. 5). A period of rainfall was defined as a separate event when the dry spell before and after the period of continuous rainfall was larger or equal than $2 \mathrm{~h}$. We determined the end point of the runoff event and separated the slow flow component as suggested by Blume et al. (2007).

Within a multivariate regression the runoff coefficients were related to different combinations of pre-event discharge ( $\left.Q_{\text {pre }}\right)$, average initial soil moisture state $\left(\theta_{\text {av }}\right)$ measured at STDR clusters $\mathrm{C} 1$ and $\mathrm{C} 2$, total precipitation $\mathrm{P}$ and maximum precipitation rate $I_{\max }$. Pre-event discharge is, as suggested by Graeff et al. (2009), a good integrated measure of the wetness state of the deep subsurface, spatial average soil moisture at the TDR clusters is regarded as a measure of the near surface soil moisture in grassland and forested landscape units. 
Table 2. Average soil properties obtained at forested site $\mathrm{C} 2, \rho$, is the bulk density.

\begin{tabular}{ccccccc}
\hline Depth $(\mathrm{cm})$ & Silt $(\%)$ & Sand $(\%)$ & Clay $(\%)$ & $k_{\mathrm{S}}(\mathrm{m} / \mathrm{s})$ & $\rho\left(\mathrm{g} / \mathrm{cm}^{3}\right)$ & Porosity $(-)$ \\
\hline 10.0 & 88.0 & 6.6 & 5.4 & $>10^{-4 \mathrm{a}}$ & $0.82 \pm 0.06$ & $0.68 \pm 0.05$ \\
20.0 & 89.0 & 6.3 & 4.7 & $2.98 \times 10^{-6}$ & $0.85 \pm 0.07$ & $0.66 \pm 0.05$ \\
50.0 & 87.0 & 10.1 & 2.9 & $4.14 \times 10^{-6}$ & $0.98 \pm 0.07$ & $0.63 \pm 0.04$ \\
\hline
\end{tabular}

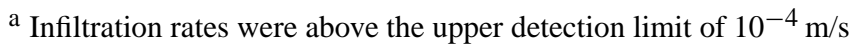

Table 3. The parameters $\theta_{\mathrm{r}}$ (residual water content), $\alpha$ (air entry value) and $n$ (width parameter) for the different layers were estimated based on the pedotransfer function of Carsel and Parrish (1998). The values were kept constant during simulation.

\begin{tabular}{cccc}
\hline Depth $(\mathrm{cm})$ & $\theta_{\mathrm{r}}\left(\mathrm{m}^{3} / \mathrm{m}^{3}\right)$ & $\alpha$ & $n(-)$ \\
\hline $0-20$ & 0.065 & 7.5 & 1.89 \\
$30-120$ & 0.078 & 3.6 & 1.56 \\
$120-200$ & 0.095 & 1.9 & 1.31 \\
\hline
\end{tabular}

Furthermore, we determined the recession coefficients for all events by plotting the logarithm of the recession discharges against time, fitting a linear function and selected those events with a coefficient of determination $\mathrm{R}^{2}$ larger or equal to 0.8 ( 8 out of 9 ). The recession constants from these events were again related to pre-event discharge and initial soil moisture observed at the grassland site $\mathrm{C} 1$ and the forested site $\mathrm{C} 2$ by means of linear regression.

\subsection{Physically based simulation of the grassland site $\mathrm{C} 1$ and the forested site $\mathrm{C} 2$}

Finally, we simulated the water balance of the grassland site and the forested site using the physically based hydrological model CATFLOW and compared averaged simulated and observed soil moisture dynamics at both sites. The idea was to investigate concurring influences of soil and vegetation parameters on the model results as well as to underpin our hypothesis that the spatial extent of the STDR clusters is large enough to assess a an unbiased spatial average soil moisture at both sites during the observation period. We think the latter is the case, if spatially homogeneous model setup that uses observed soil hydraulic data allows unbiased reproduction of the mean dynamics.

\subsubsection{Model characterization}

CATFLOW allows physically-based simulations of flow and solute transport at the hillslope and small catchment scales (Maurer, 1997; Zehe et al., 2001). The model represents a hillslope along the steepest descent line as a 2-dimensional cross section that is discretized by 2 -dimensional curvilin- ear orthogonal coordinates. The hillslope is thus assumed to be uniform perpendicular to the slope line. Soil water dynamics is described by the Richards equation in the potential form that is numerically solved by an implicit mass conservative Picard iteration (Celia and Bouloutas, 1990). Accordingly, the model allows simulation of subsurface flow under saturated and unsaturated conditions. Soil hydraulic functions are described after van Genuchten (1980) and Mualem (1976). Evaporation and transpiration is simulated using an advanced approach based on the Penman-Monteith equation, which accounts for annual cycles of plant morphological and plant physiological parameters, albedo as a function of soil moisture and the impact of local topography on wind speed and radiation. In the case of infiltration excess or saturation excess, surface runoff is routed along the main slope line and using the convection-diffusion approximation of the onedimensional Saint-Venant equation. It is numerically solved by an explicit upstream finite difference scheme.

\subsubsection{Model setup and simulation variants}

The concurring influences of soil hydraulic parameters and plant morphological parameters on soil moisture were investigated in a two step procedure to find the most parsimonious model setup that allows successful prediction of the time series of observed average soil moisture at both sites.

The $35 \mathrm{~m}$ long hillslopes were discretized into a twodimensional finite difference grid. Vertical resolution was $2 \mathrm{~cm}$ in the upper $60 \mathrm{~cm}$ and $20 \mathrm{~cm}$ down to $2 \mathrm{~m}$ depth. Lateral resolution was $0.5 \mathrm{~m}$. Surface model elements extend over a width of $26 \mathrm{~m}$ which corresponds to the width of the hillslopes. Both model hillslopes were thus assigned a homogeneous three-layer soil profile, neglecting stochastic variability of soil parameters as first guess. In a first step we compared 3 different soil profiles A, B, C and used vegetation parameters for forest and grassland that have been determined in the Weiherbach catchment (see next section). The van Genuchten parameters $\theta_{\mathrm{r}}$ (residual water content), $\alpha$ (air entry value) and $n$ (width parameter) in the different layers were estimated based on the available texture data using the pedotransfer function of Carsel and Parrish (1988) and kept constant during the simulations (Table 3). The saturated hydraulic, $k_{\mathrm{s}}$, conductivity and porosity, $\theta_{\mathrm{s}}$, varied within the three soil profiles. Profile A and B use for the 
Table 4. Saturated hydraulic conductivity $\left(k_{\mathrm{S}}\right)$ and porosity $\left(\theta_{\mathrm{S}}\right)$ played through in the different profiles. Profile A and B use for the upper two layers the average values observed at the grassland and the forested site, respectively. The deep layer is parameterized according to Carsel and Parrish (1988). Profile C used in all layers values derived by Carsel and Parrish (1998).

\begin{tabular}{ccccccc}
\hline & Profile A & \multicolumn{3}{c}{ Profile B } & \multicolumn{2}{c}{ Profile C } \\
\hline $\begin{array}{c}\text { Depth } \\
(\mathrm{cm})\end{array}$ & $\begin{array}{c}k_{\mathrm{s}} \\
(\mathrm{m} / \mathrm{s})\end{array}$ & $\begin{array}{c}\theta_{\mathrm{s}} \\
\left(\mathrm{m}^{3} / \mathrm{m}^{3}\right)\end{array}$ & $\begin{array}{c}k_{\mathrm{s}} \\
(\mathrm{m} / \mathrm{s})\end{array}$ & $\begin{array}{c}\theta_{\mathrm{s}} \\
\left(\mathrm{m}^{3} / \mathrm{m}^{3}\right)\end{array}$ & $\begin{array}{c}k_{\mathrm{s}} \\
(\mathrm{m} / \mathrm{s})\end{array}$ & $\begin{array}{c}\theta_{\mathrm{s}} \\
\left(\mathrm{m}^{3} / \mathrm{m}^{3}\right)\end{array}$ \\
\hline $0-20$ & $4.16 \times 10^{-5}$ & 0.63 & $1.23 \times 10^{-4}$ & 0.68 & $1.23 \times 10^{-5}$ & 0.50 \\
$30-120$ & $1.58 \times 10^{-6}$ & 0.61 & $2.89 \times 10^{-6}$ & 0.66 & $2.89 \times 10^{-6}$ & 0.52 \\
$120-200$ & $7.22 \times 10^{-7}$ & 0.41 & $7.22 \times 10^{-7}$ & 0.41 & $7.22 \times 10^{-7}$ & 0.41 \\
\hline
\end{tabular}

upper two layers the average values observed at the grassland and the forested site, respectively. The deep layer is parameterized according to Carsel and Parrish (1988). Profile $\mathrm{C}$ used in all layers values derived by Carsel and Parrish (1998), assuming that only texture data were available (Table 4). Please note that the porosities and hydraulic conductivities are clearly smaller Simulation results were evaluated using the root mean square error (RMSE), the absolute bias (Bias) and the correlation coefficient $R$.

In the next step we selected the best suitable soil profile and adjusted vegetation and landuse parameters. The latter include the annual cycles of plant morphological parameters (leaf area index LAI, plant cover, root depths, plant height, as well as plant roughness), as well as several parameters that control the evapo-transpiration model such as plant albedo, minimal stomata resistance, a factor and an inflexion point parameter of the soil moisture weighting function for stomata resistance computation (Zehe et al., 2001). These parameters as well as the annual cycles of plant morphological parameters were determined for different crops, forest and grassland in the Weiherbach catchment in South West Germany based on detailed field survey, remote sensing and process model studies (Zehe et al., 2001). Plant physiology may be assumed to be independent from the catchment setting. We thus took over the complete corresponding parameters sets. However, the annual cycles of plant phonological parameters such as LAI, plant cover and also root depth depend of course on the climate setting and climate in the Rehefeld is on average three degrees cooler than in the Weiherbach catchment. We thus normalised the annual cycles of plant morphological parameters from the Weiherbach dataset by dividing the daily values by their annual maxima. LAI, plant cover and root depth of these normalized annual cycles range thus from zero to one. By multiplying these normalized annual cycles by slightly different annual maxima of LAI, plant cover and root depth we were able to test slightly different annual cycles during different simulations. The combinations of LAI maxima, plant cover maxima and root depths that were played through will be presented in the results section.. As quality criteria we used again the RMSE, the bias and $R$.
The upper boundary condition during simulation was atmospheric based on the observed precipitation and meteorological data observed at $\mathrm{C} 1$. At the lower boundary we established gravity flow. The left boundary condition at the hill top was set to zero flow; the right boundary condition was a seepage interface to allow subsurface flow to exfiltrate from the hillslope. Simulation started at 1 March 2007, which was already snow free, to assure a sufficiently long initialization period and lasted up to 26 October 2008.

\section{Results}

\subsection{First and second spatial moment}

Figure 2 gives a first overview on the precipitation input and temperature forcing ( $\mathrm{a}$ and $\mathrm{b}$ ) during the observation period in Summer 2007 as well as on the time series of vertical average soil water content for the individual probes for cluster $\mathrm{C} 1$ at the grassland site (c) and C2 at the forested site (d). The period of missing data was due to a break-down of the multiplexers that took a while to be fixed. The total range of water content values within the probes of cluster $\mathrm{C} 2$ is smaller compared to cluster $\mathrm{C} 1$. The most downslope TDR probe at $\mathrm{C} 2$ is influenced by shallow groundwater and is consequently very wet during the entire period. The probes at the dry end of the spectrum are installed in a debris-rich fast-draining spot. At both sites there is a small daily course in measured soil water contents. The amplitude is of order $0.002 \mathrm{~m}^{3} \mathrm{~m}^{-3}$, correlation with air temperature is negative and strongest at a lag of $12 \mathrm{~h}$. The negative correlation could be explained by evaporation and transpiration loss during the day which is regained due to dew formation during the night. A daily fluctuation of $0.002 \mathrm{~m}^{3} \mathrm{~m}^{-3}$ in soil water content at a porosity of 0.6 and along a length of $60 \mathrm{~cm}$ corresponds to a evaporation loss of $0.8 \mathrm{~mm}$ during daytime. This appears to be reasonable.

Figure 3 ( $a$ and $b$ ) compares time series of the first two spatial moments at both clusters. The temporal dynamics of the spatial means at both sites looks similar to a hydrograph, fast rising "peaks" and long "recessions". Average soil moisture at the grassland site is significantly larger than at the forested 

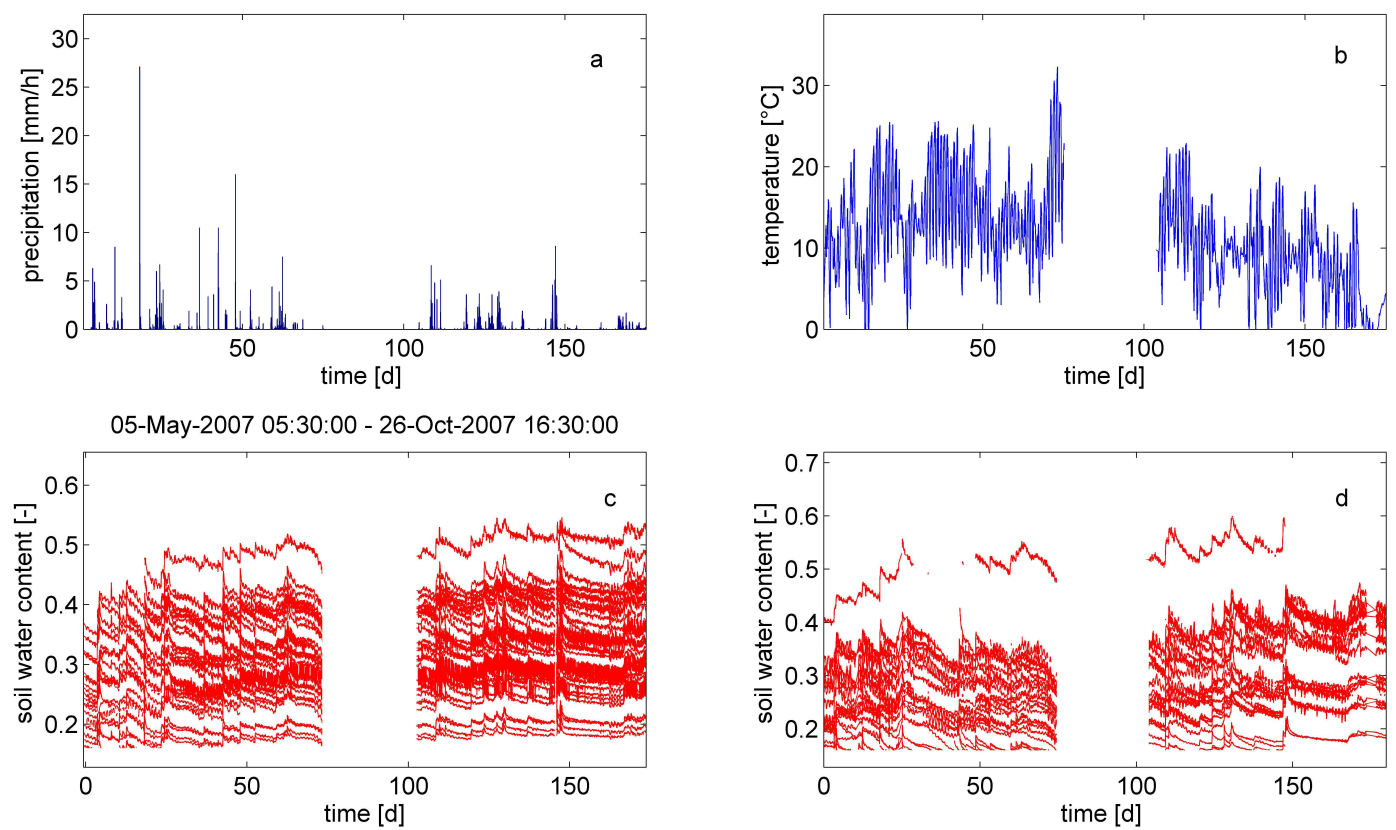

Fig. 2. Precipitation (a) and air temperature (b) in the observation period, vertically average soil water content at probe locations at $\mathrm{C} 1$ (c) and C2 (d). Period starts at 3 May 2007 and end at 26 October 2007.
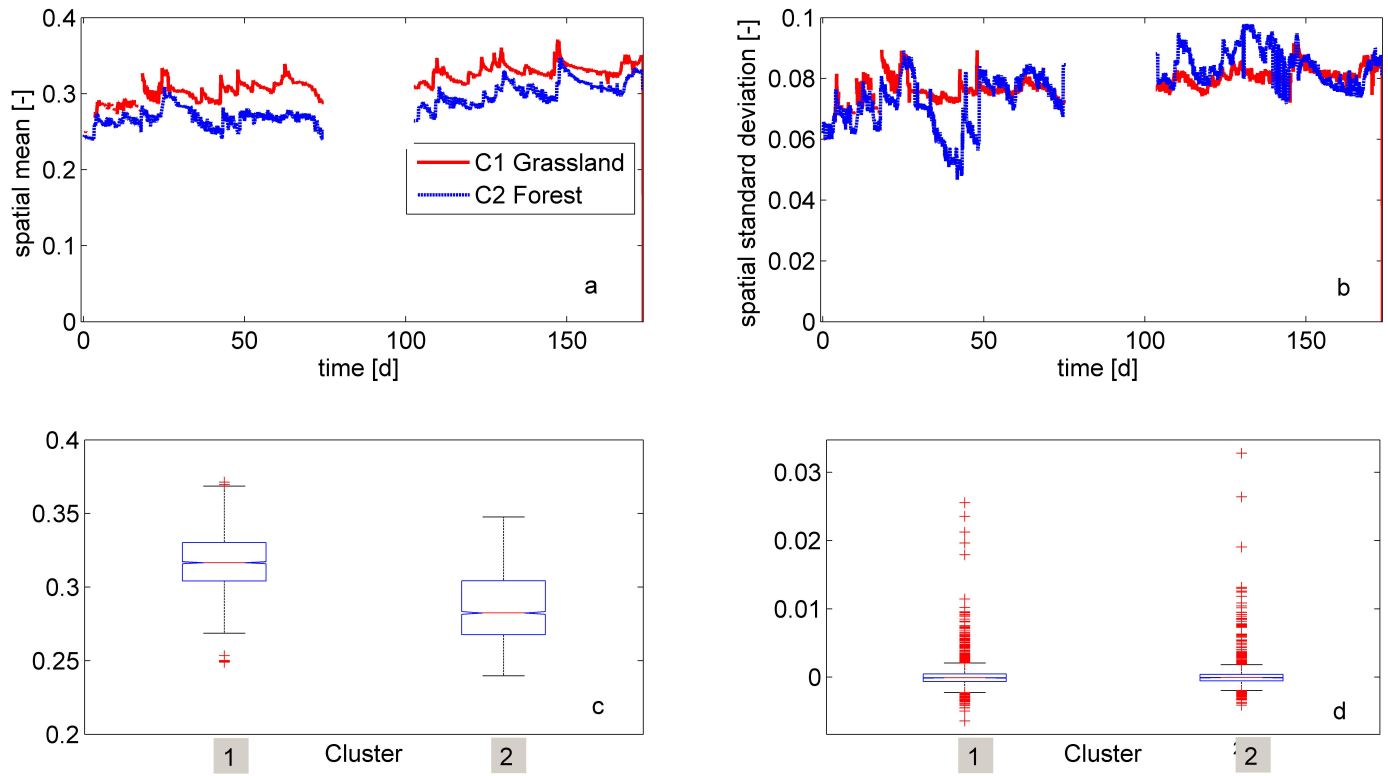

Fig. 3. Time series of spatial average soil water content and spatial standard deviation at both clusters (a and b), box plots of spatial average soil water content and of the spatial average soil water increments (difference between values at two adjacent time steps, $\mathbf{c}$ and $\mathbf{d}$ ). Period starts at 3 May 2007 and end at the 22 August 2007.

site as can be depicted from the box plots in the Fig. 3c. Coefficients of variations (not shown) at both sites are pretty constant at the grassland site with on average 0.22 and a narrow range between 0.23 and 0.2 compared to $\mathrm{C} 2$ where the relative spatial variability is fluctuating between 0.22 and 0.15 with an average around 0.18 . The Pearson correlation coefficient between the time series of spatial average soil moisture at both sites is 0.76 . Thus, $50 \%$ of the temporal soil moisture variance observed at one site may be explained by the variance observed at the other site. As the climate forcing is supposed to be very similar we conclude that $50 \%$ of the soil variance is determined by climate conditions, the rest is determined by soil and vegetation. 

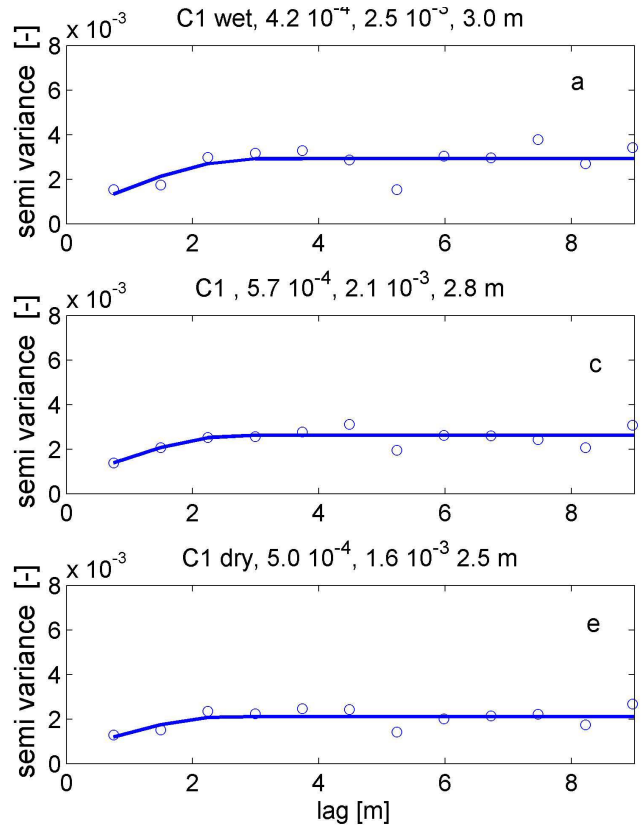
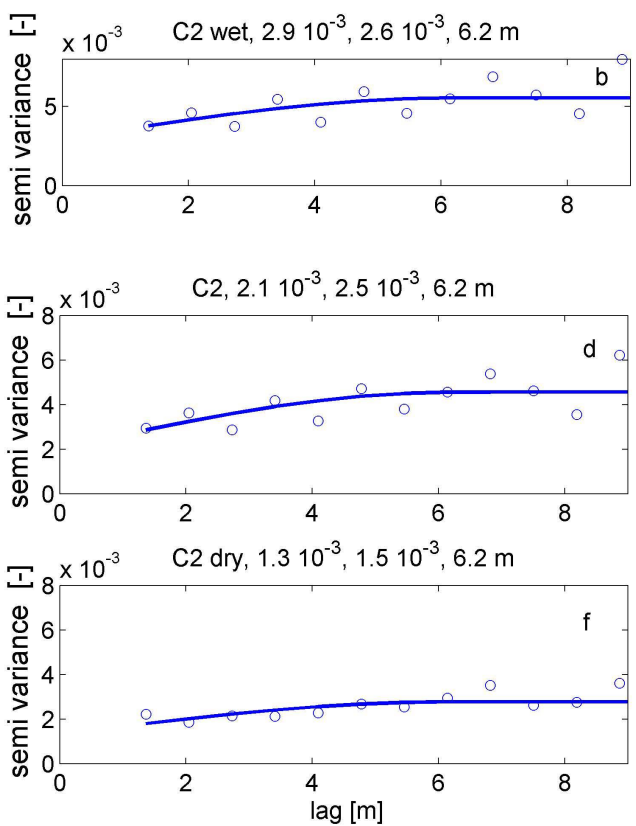

Fig. 4. Experimental variogram and fitted spherical variograms for both sites (left column of panels is $\mathrm{C} 1$, the right is $\mathrm{C} 2$ ). Upper panels represent average wet conditions, middle overall average conditions and lower panels average dry conditions. The panel headers list the nugget, sill and range of the fitted spherical variogram function.

As can be seen from the box plots in the Fig. 3c, the spatial mean of soil moisture within the upper $60 \mathrm{~cm}$ is on average $0.04 \mathrm{~m}^{3} \mathrm{~m}^{-3}$ larger than at the forested site $\mathrm{C} 2$. The marginal soil moisture distribution at C2 is clearly skewed towards the right; at $\mathrm{C} 1$ it is rather symmetrical. Hourly soil moisture changes at both sites are on average zero (Fig. 3d). Their marginal distributions appear rather similar. The second spatial moments of hourly soil moisture changes are small, at around $0.001 \mathrm{~m}$ at both sites. The coefficients of variation of hourly soil moisture changes are, however, very large, with values up to 100 . This highlights that the relative spatial variability of the hourly soil moisture changes are large when compared to the relative spatial variability of the absolute moisture values, which underpins the heterogeneity of this site.

\subsection{Average covariance structure}

The correlation length of the long-term averages of soil water content at individual probes at $\mathrm{C} 1$ turned out to be $2.8 \mathrm{~m}$ (Fig. 4c). This small value is not astonishing due to the large small-scale heterogeneity observed at this site. Gravel content and porosity especially vary strongly between neighboring plots. For wet/dry conditions the range shows a slight increase/decrease of $0.2 \mathrm{~m}$. The sill to nugget ratio - a measure for the part of the variability that is explained by the variogram - increases from dry to average to wet conditions as $3 / 1$ over $4 / 1$ to $5 / 1$. This finding, and the increasing correlation length with increasing wetness, is consistent with find- ings of Western et al. (2004) or Grayson et al. (1997). However, contrary to their findings, in our case total soil moisture variance (nugget + sill) in $\mathrm{C} 1$ increases with increasing average wetness (Fig. 4a). This due to the fact that a few probes are located in gravel-rich soil spots which drain very fast due to the high permeability and low water retention. These probes stay relatively dry even when the rest of the field wets up during rainfall events. Brocca et al. (2007) found at their grassland site in the upper Tiber valley effective ranges that were approximately 28-35 meter and also a nugget of sill ratio that changed with average saturation.

At the forested site, $\mathrm{C} 2$ correlation length does not vary with average wetness and is - at $6.2 \mathrm{~m}$ - roughly $50 \%$ of the maximum probe distance (Fig. $4 \mathrm{~b}, \mathrm{~d}, \mathrm{e}$ ). Also the sill to nugget ratio is almost constant at approximately $1: 1$. Also here total variance is maximum in the wet case and minimum in the dry case. The reason is the same as in the case of $\mathrm{C} 1$ : some spots of high permeability never really wet up due to fast drainage. The constant correlation length and the constant nugget to sill ratio reflect the stationary pattern of throughfall within this spring/summer period. Disturbances due to large rain events are simply filtered out as we deal with temporally-averaged data that reflect average dry, total average and average wet conditions at the probes. 
Table 5. Coefficients of determination $\left(R^{2}\right)$ obtained within multivariate/univariate regressions that used pre-event discharge ( $\left.Q_{\text {pre }}\right)$, average initial soil moisture state $\left(\theta_{\mathrm{av}}^{\mathrm{C} 1}, \theta_{\mathrm{av}}^{\mathrm{C} 2}\right)$, measured at STDR clusters, total precipitation $P$ and maximum precipitation rate $I_{\mathrm{max}}$ as explaining variables. An $\mathrm{X}$ indicates whether that a variable was included as explaining variable.

\begin{tabular}{ccccccc}
\hline Variables & $Q_{\mathrm{pre}}\left[\mathrm{m}^{3} / \mathrm{s}\right]$ & $\theta_{\mathrm{av}}^{\mathrm{C} 1}[-]$ & $\theta_{\mathrm{av}}^{\mathrm{C} 2}[-]$ & $P[\mathrm{~mm}]$ & $I_{\max }[\mathrm{mm} / \mathrm{h}]$ & $R^{2}$ \\
\hline Regression 1 & $\mathrm{X}$ & & & & & 0.59 \\
Regression 2 & & $\mathrm{X}$ & &. & & 0.49 \\
Regression 3 & & & $\mathrm{X}$ & & & 0.92 \\
Regression 4 & $\mathrm{X}$ & $\mathrm{X}$ & & & & 0.61 \\
Regression 5 & $\mathrm{X}$ & & & $\mathrm{X}$ & $\mathrm{X}$ & 0.70 \\
Regression 6 & & & $\mathrm{X}$ & $\mathrm{X}$ & & 0.93 \\
Regression 7 & & & $\mathrm{X}$ & $\mathrm{X}$ & $\mathrm{X}$ & 0.94 \\
Regression 8 & $\mathrm{X}$ & $\mathrm{X}$ & $\mathrm{X}$ & $\mathrm{X}$ & $\mathrm{X}$ & 0.94 \\
\hline
\end{tabular}
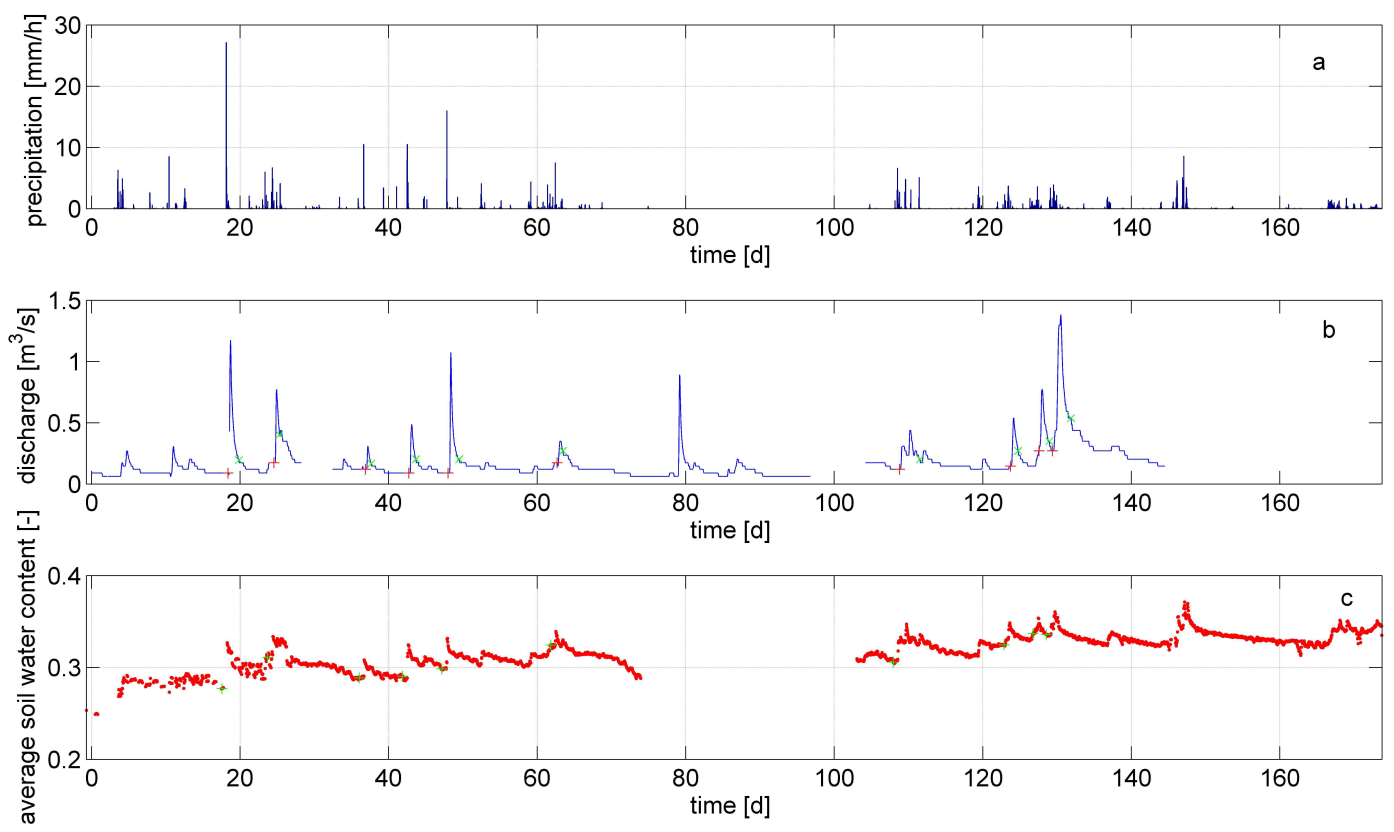

Fig. 5. Rainfall (a), average soil moisture at cluster C1 (c) and discharge (b) at the Rehefeld gauge. The Pearson correlation between average soil moisture and discharge is 0.35 .

\subsection{Soil moisture and subsurface wetness control on runoff generation}

Figure 5 shows the rainfall time series (a), discharge response at gauge Rehefeld (b) as well as the time series of spatial average soil moisture at the grassland cluster C1 (c). The Pearson correlation coefficient between average soil moisture and discharge is 0.35 and significantly non zero at a confidence level of $95 \%$. Table 5 provides coefficients of determination obtained within 5 regressions. Average initial soil moisture at the grassland site alone explains $50 \%$ of the variability of the runoff coefficients (compare also Fig. 6a). Pre-event discharge explains as expected even $60 \%$ of the variability (Fig. 6b). The strong dependence on pre-event discharge suggests that the wetness state of the deep subsurface is an important control of runoff generation at the Rehefeld catchment. The strongest relation was, however, found for average antecedent soil moisture at the forested site, as it explains $92 \%$ of the variability of the observed runoff coefficients. This is remarkably, as the catchment is with $16 \mathrm{~km}^{2}$ more than five orders of magnitude larger than the total extent of the TDR cluster C2. Cluster C2 extends from the floodplain of the Becher Bach, a small tributary of the Wilde Weißeritz, upslope to an elevation of roughly $15 \mathrm{~m}$ above the brook. This suggests that the wetness state of the lower hillslope sector in forested sites is much more important for event runoff generation as the entire wetness state of the deep catchment store. The squared correlation between average soil moisture 

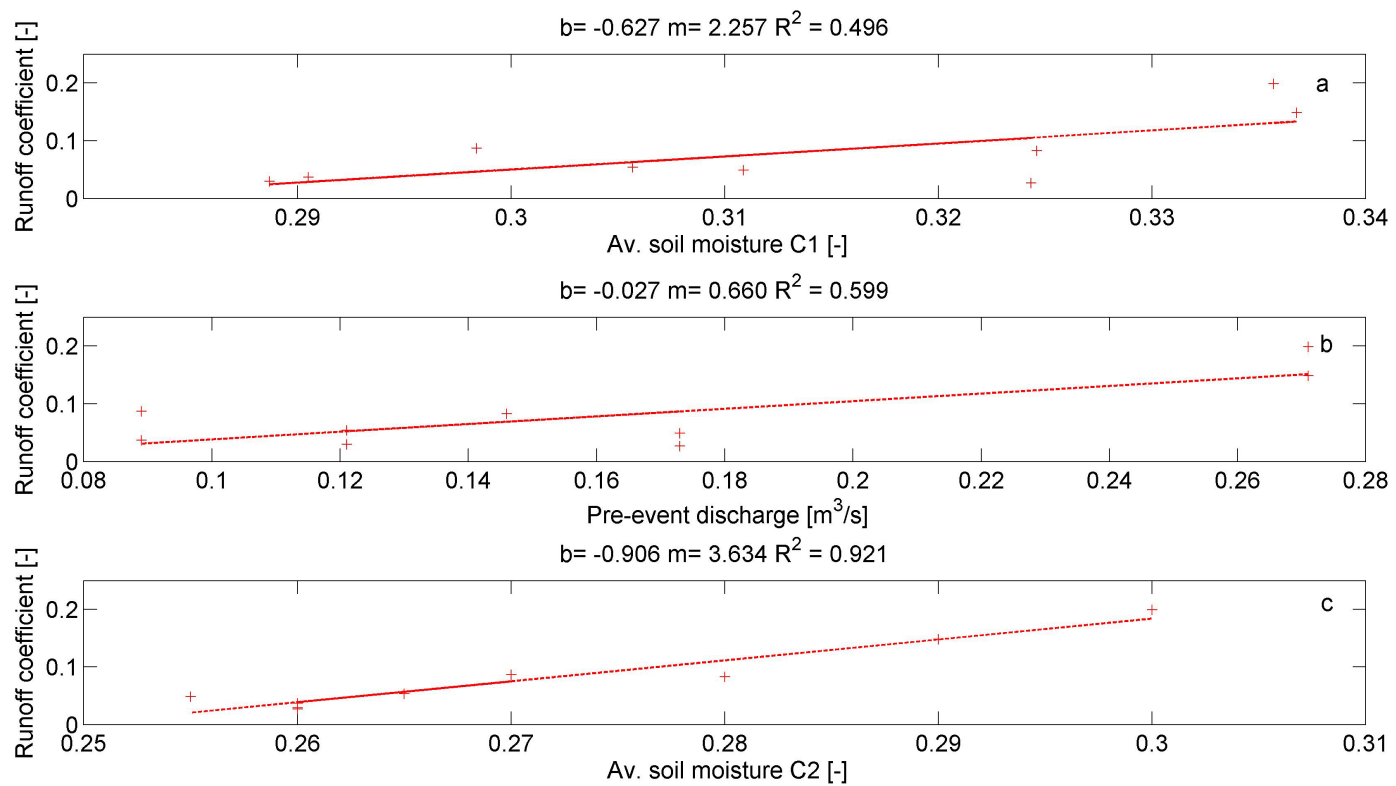

Fig. 6. Scatter plots of the runoff coefficients against average initial soil moisture observed at the grassland site $\mathrm{C} 1$ (a), with pre event discharge (b), as well as average initial soil moisture at the forested site C2 (c). The regression parameter $b, m$ and $R^{2}$ denote the intercept at the $y$-axis, the slope of the regression function as well as the coefficient of determination.

at the grassland site and pre-event discharge is, with an $R^{2}$ of 0.77 , much stronger than the corresponding correlation between average antecedent soil moisture at the forested site and pre-event discharge (which is 0.5). Prevent discharge, the precipitation sum and maximum precipitation intensity explain together $70 \%$ of the variability of the runoff coefficients (Table 5). This highlights, consistently with findings of Brocca et al. $(2007,2009)$ and Anctil (2008), that representative soil moisture data in key areas are of much higher value for explaining and predicting runoff production than those predictors one would usually employ without available soil moisture data.

Figure 7 shows scatter plots of the recession coefficients determined for the 9 events plotted against pre event discharge (Fig. 7a) and average soil moisture initial soil moisture at the grassland (Fig. 7b) and forested site (Fig. 7c). Recession constants decrease with increasing pre-event discharge/initial soil moisture. This means that recession process becomes slower when the catchment, especially the forested part, becomes wetter. Antecedent soil moisture at the forested site explains $93 \%$ of the variability of the recession coefficients.

\subsection{Simulated average soil moisture dynamics at the seasonal scale}

\subsubsection{Model sensitivity to different soil profiles}

As can be seen from Table 6 soil profile A allows yields the best model performance for the grassland site, whereas pro- file B allows the best model performance for the forested site. This underpins the value of observed soil hydraulic data, as both profiles use data that were measured at the respective sites. Profile $\mathrm{C}$ which has a smaller porosity and smaller ks causes at both sites the highest bias, the worst correlation and RMSE, respectively.

\subsubsection{Model fine tuning with LAI, plant cover and root depth}

Table 7 lists the annual maxima of leaf area index, plant cover and root depth played through during the model fine tuning as well as corresponding model goodness parameters. The annual maxima observed in the Weiherbach catchments are printed in bold italics, the best parameter sets are obtained at both site are printed in bold (compare Fig. 8). As can bee seen from Table 7 slight changes in the annual maxima of LAI and plant cover yielded a clear improvement of the model performance. Figure $8 \mathrm{~b}$ highlights the surprisingly good accordance of the averaged simulated soil water content in the upper $60 \mathrm{~cm}$ with the average soil moisture observed at the forested site. Despite small overestimation of the soil moisture peaks during rainfall events the averaged simulated soil moisture is most times within the confidence interval of the observed average soil moisture. The confidence interval was estimated by dividing the standard deviation within a cluster by the square root of the number of sensors that were available at this date. It is furthermore remarkable that simulated averaged soil moisture is still a good match for the observations even after the period of missing data. We may thus 

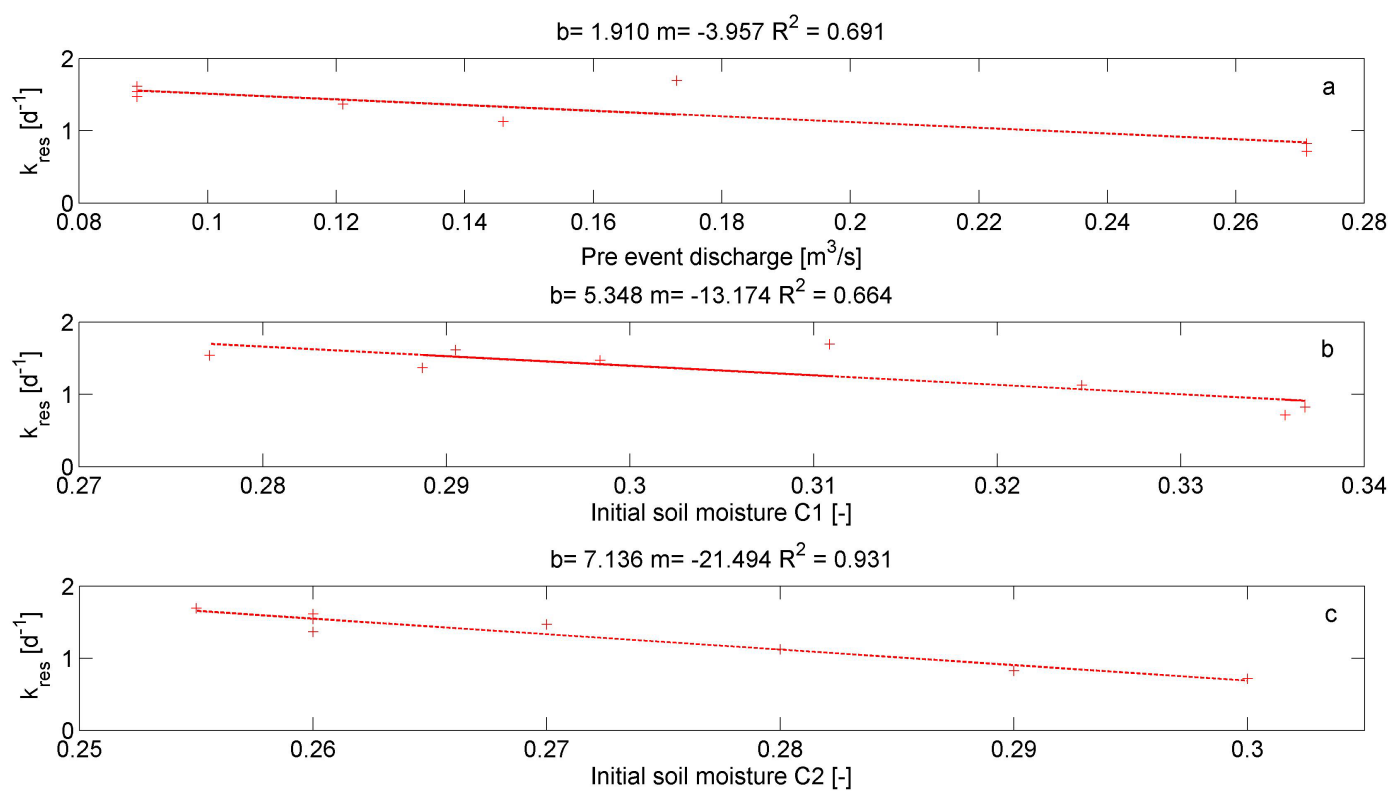

Fig. 7. Scatterplots of the recession coefficients $k_{\text {res }}$ against average initial soil moisture observed at the grassland site $\mathrm{C} 1$ (a), with pre-event discharge (b) as well as as well as average initial soil moisture at the forested site C2 (c). The regression parameter $b, m$ and $R^{2}$ denote the intercept at the y-axis, the slope of the regression function as well as the coefficient of determination.
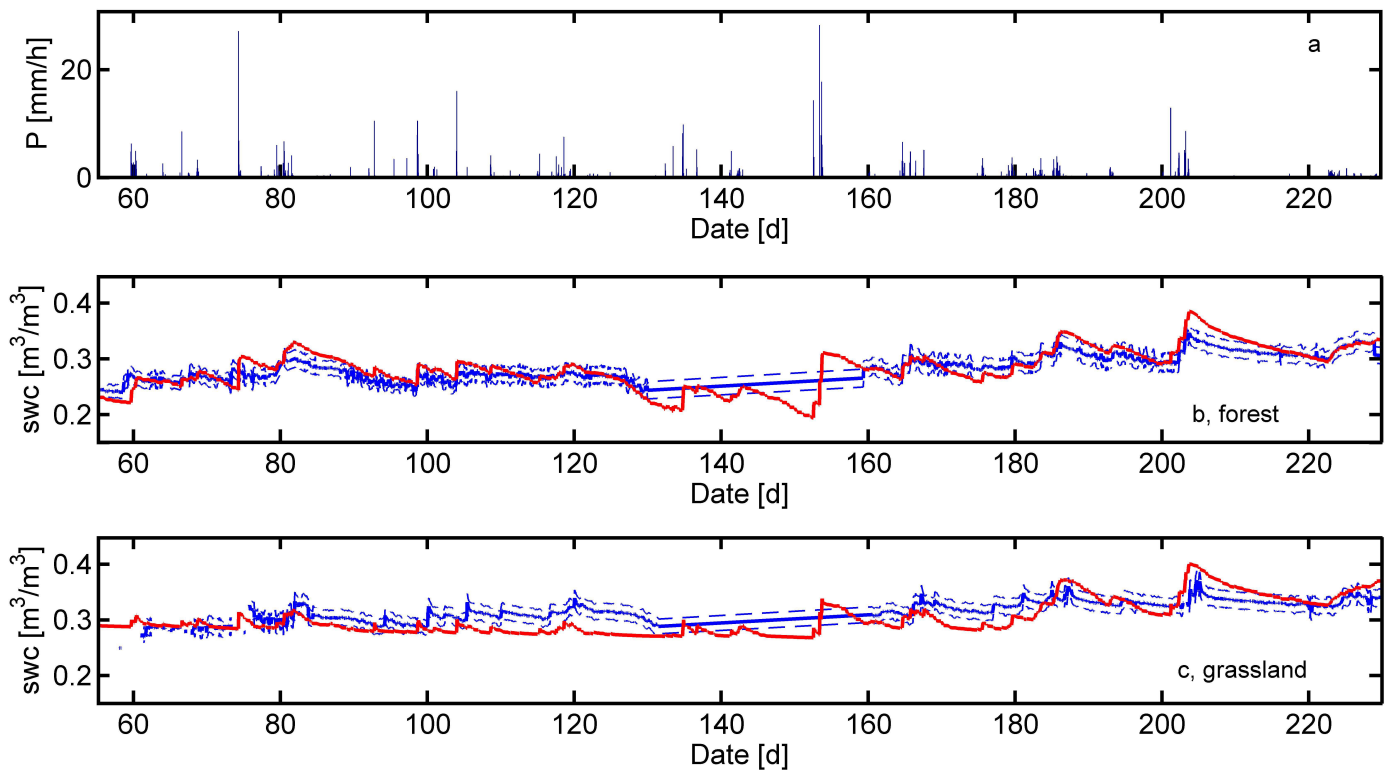

Fig. 8. Precipitation observed at grassland site C1 (a), spatially averaged soil water content; swc in the upper $60 \mathrm{~cm}$ simulated with Catflow (solid red line), observations (solid blue line) and confidence interval of the spatial average soil moisture (dashed blue line) for the grassland site $\mathrm{C} 1$ (c) and the forested site $\mathrm{C} 2$ (b). The confidence interval was estimated by dividing the standard deviation within a cluster by the square root of the number of sensors that were available at this date. The plotted period starts at 5 May and ends at 26 October 2007. Please note that the period between day 120 and 160 is a period of missing data.

state that a good prediction of soil moisture at the forested site is possible when using the normalized annual cycles of plant morphological parameter observed in the Weiherbach catchment and a slight adaptation of the annual maxima of LAI and plant cover.
Reproduction of the observed average soil moisture time series at the grassland site was not that straight forward, although we played through a much wider range of parameters including variations of root depth (Table 7). The best simulation, parameters are printed in bold, has higher RMSE, larger 
Table 6. Root means square error (RMSE, scale is $10^{-4}$ ), bias (scale is $10^{-3}$ ) and correlation between simulated and observed average soil moisture obtained with the three different soil profiles (compare Tables 3 and 4 for soil parameters).

\begin{tabular}{ccccccc}
\hline \multicolumn{4}{c}{ Grassland } & \multicolumn{3}{c}{ Forest } \\
\hline Profile & $\begin{array}{c}\text { RMSE/10 } \\
{[-4}\end{array}$ & $\begin{array}{c}\text { Bias/10 } \\
{\left[\mathrm{m}^{3} \mathrm{~m}^{-3}\right]}\end{array}$ & $\begin{array}{c}R \\
{[-]}\end{array}$ & $\begin{array}{c}\text { RMSE/10 } \\
{[-]}\end{array}$ & $\begin{array}{c}\text { Bias/10 } \\
{\left[\mathrm{m}^{3} \mathrm{~m}^{-3}\right]}\end{array}$ & $\begin{array}{c}R \\
{[-]}\end{array}$ \\
\hline A & 6.9 & 14 & 0.753 & 78.2 & 47 & 0.725 \\
B & 27 & -60 & 0.010 & 10.4 & 32 & 0.850 \\
C & 33 & -74 & 0.169 & 18.0 & -54 & 0.630 \\
\hline
\end{tabular}

Table 7. Annual maxima of leaf area index (LAI), plant cover and root depth played through during the model fine tuning and corresponding model goodness parameters root means square error (RMSE, RMSE, scale is $10^{-4}$ ), bias (scale is $10^{-3}$ ) and correlation. The annual maxima observed in the Weiherbach catchments are in bold italics, the best parameter sets are in bold (compare Fig. 8).

\begin{tabular}{lcccccc}
\hline Site & $\begin{array}{c}\text { LAI } \\
{\left[\mathrm{m}^{2} \mathrm{~m}^{-2}\right]}\end{array}$ & $\begin{array}{c}\text { Plant cover } \\
{[-]}\end{array}$ & $\begin{array}{c}\text { Root depth } \\
{[\mathrm{m}]}\end{array}$ & $\begin{array}{c}\text { RMSE } / 10^{-4} \\
{[-]}\end{array}$ & $\begin{array}{c}\text { Bias } / 10^{-3} \\
{\left[\mathrm{~m}^{3} \mathrm{~m}^{-3}\right]}\end{array}$ & $\begin{array}{c}R \\
{[-]}\end{array}$ \\
\hline Forest & 13.5 & 0.9 & 1 & 5.4 & 11 & 0.892 \\
Forest & 14.0 & 0.8 & 1 & 10.4 & 32 & 0.850 \\
Forest & $\mathbf{1 4 . 0}$ & $\mathbf{0 . 9}$ & $\mathbf{1}$ & $\mathbf{1 0 . 4}$ & $\mathbf{3 2}$ & $\mathbf{0 . 8 5 0}$ \\
Forest & 14.0 & 0.85 & 1 & 8.1 & 23 & 0.876 \\
Forest & 13.5 & 0.8 & 1 & 5.1 & 9.2 & 0.891 \\
Forest & $\mathbf{1 3 . 5}$ & $\mathbf{0 . 8 5}$ & $\mathbf{1}$ & $\mathbf{4 . 7}$ & $\mathbf{5 . 7}$ & $\mathbf{0 . 8 8 9}$ \\
Grassland & 4 & 1 & 0.2 & 7.0 & -12 & 0.727 \\
Grassland & 5 & 1 & 0.2 & 7.2 & -14 & 0.716 \\
Grassland & 6 & 1 & 0.2 & 7.5 & -16 & 0.71 \\
Grassland & 4 & 1 & 0.3 & 10.1 & -24 & 0.655 \\
Grassland & $\mathbf{5}$ & $\mathbf{0 . 9}$ & $\mathbf{0 . 2}$ & $\mathbf{6 . 8}$ & $-\mathbf{8}$ & $\mathbf{0 . 7 4 9}$ \\
Grassland & 5 & 0.9 & 0.3 & 9.2 & -19 & 0.700 \\
Grassland & 6 & 0.9 & 0.2 & 7.0 & -10 & 0.743 \\
Grassland & 6 & 0.9 & 0.3 & 9.5 & -20 & 0.695 \\
Grassland & $\mathbf{4}$ & $\mathbf{1}$ & $\mathbf{0 . 1}$ & $\mathbf{6 . 9}$ & $\mathbf{1 4}$ & $\mathbf{0 . 7 5 3}$ \\
Grassland & 4 & 0.95 & 0.1 & 7.3 & 16 & 0.763 \\
Grassland & 4 & 0.9 & 0.1 & 8.4 & 20 & 0.780 \\
Grassland & 3.5 & 1 & 0.1 & 7.0 & 15 & 0.751 \\
Grassland & 3.5 & 0.95 & 0.1 & 7.6 & 17 & 0.763 \\
Grassland & 3.5 & 0.9 & 0.1 & 9.2 & 22 & 0.788 \\
Grassland & 3.0 & 1 & 0.1 & 7.6 & 16 & 0.762 \\
Grassland & 3.0 & 0.95 & 0.1 & 8.5 & 20 & 0.776 \\
\hline
\end{tabular}

bias and smaller correlation coefficient when compared to the best simulation at the forested site. Figure 8c shows that the model systematically underestimates soil moisture between day 100 and day 160 which corresponds to the period between mid of June to start of September. We may thus state that even a strong variation of the annual maxima of LAI, plant cover and root depth, while leaving the normalized annual cycle unchanged, is obviously not sufficient to match observed soil moisture dynamics similar well as at the forested site.

\section{Discussion and conclusions}

\subsection{Deterministic and stochastic soil moisture variability}

The analysis presented gives clear evidence that clustering of TDR probes, even if they simply yield the usual vertical average, allows identification of deterministic soil moisture variability, i.e. the difference between the first and second moment, and even allows a first glance at the differences in higher moments such as skewness of the two soil moisture ensembles. Spatial variability of water content values is quite 
large at both sites, between $0.07 \mathrm{~m}^{3} / \mathrm{m}^{3}$ and $0.08 \mathrm{~m}^{3} / \mathrm{m}^{3}$. This is considerably larger than what has been observed in the Weiherbach catchment in Germany (Bárdossy and Lehmann, 1998), or in the upper Tiber valley by Brocca et al. (2007) but comparable to what Blume et al. (2009) observed in the Mallalcahuello catchment in Chile. The total extent of the clusters at $400 \mathrm{~m}^{2}$ is rather small. This underpins that a single TDR probe is not very useful to assess the representative average soil moisture states in such a heterogeneous environment. On the other hand, Brocca et al. $(2007,2009)$ reports consistent with the findings of Grayson and Western (1998) the existence of representative monitoring sites, where the observed soil moisture was on the weekly scale always close to the overall spatial average of the field/ catchment. However, such sites may not be identified a priory, which underpins the value of any kind of distributed soil moisture observations in general.

It is interesting and important to note that the soil moisture time series in Fig. 2 do not intersect. The ranks of the soil moisture values observed at different locations in a cluster remain thus temporarily stable. Also Brocca et al. (2007) report temporal stability of the ranks within their soil moisture data sets. These findings suggest that the spatial variability in soil water content measurements reflects spatial heterogeneity of stationary soil properties as well as of the micro topography. Soil moisture time series within each cluster are furthermore highly correlated (0.90), which underpins that the dynamics observed at a single probe is a good estimator for average soil moisture dynamics at the small field scale in the Rehefeld catchment. Thus, a distributed set of single TDR stations may yield representative information on temporal soil moisture dynamics at the headwater scale, which can be very important information for many modeling studies and maybe even for flood warning purposes, as shown for instance shown by Anctil et al. (2008) in the Orgeval watershed.

Furthermore, we found clear evidence that clustering of TDR probes in combination with long-term monitoring allows identification of average spatial covariance structures at the small field scale at different wetness states. We have to admit that the small extent of cluster C2 likely gives only a limited picture of the spatial covariance of soil moisture at the forested site. The estimated range is almost $50 \%$ of the maximum probe distance, which is the theoretical limit. Distributed sampling that covers a larger extend is clearly desirable here. Spatial correlation length at the grassland site seems in contrast to be rather short, due to small-scale heterogeneity in soil properties. Zimmermann et al. (2008) found a similar small correlation length for the hydraulic conductivity at a steep grassland site in Ecuador. Brocca et al. (2007) found at their grassland site in the upper Tiber valley effective ranges that were approximately 10 times larger. The much shorter ranges at our site may be explained with the huge small scale heterogeneity due to the high gravel content of these soils. It is important to note that the small-scale het- erogeneity of soil properties at the forested site is similar to the grassland site. We therefore conclude that the correlation structure at the forested site is dominated by the pattern of throughfall and interception and therefore vegetation; at site $\mathrm{C} 1$ it is dominated by small-scale variability of soil properties. This is of course not a big surprise for a forested site: the important point is that a cluster of TDR probes allows quantification of such a statement.

\subsection{Soil moisture control on event runoff}

Strikingly, average antecedent soil moisture at the forested site explained almost $92 \%$ of the observed runoff coefficients and was clearly better than all combinations of preevent discharge, precipitation sum, maximum intensity, average antecedent at the grassland site we played through. Preevent discharge alone explained also $60 \%$ of the observed runoff coefficients and was strongly correlated to average soil moisture at the grassland site. We thus conclude that subsurface storm flow or fast groundwater flow is the domination the runoff generating process, at least in the snowfree period. We think that saturation excess overland flow plays due to the high porosity of the top soil, which is more than $0.60 \mathrm{~m}^{3} \mathrm{~m}^{-3}$, and the large amount of gravel a minor role. Subsurface storm flow is reported to be the dominant runoff process in many other studies in forested areas (Zehe and Sivapalan, 2009) such as those of Blume et al. (2008a, b), Tromp-van-Meerveld et al. (2006) and Uhlenbrook et al. (2002). Interestingly, the wetness state of the lower hillslope sector in forested sites seems to be of higher importance for event runoff production than average catchment wetness represented by pre-event discharge. We thus conclude that in the Rehefeld catchment forested sites likely contribute stronger to event scale runoff production as grass land. This highlights that spatio temporarily highly resolved sampling of representative soil moisture data in key landscape units resolution might yield very valuable information for explaining and predicting runoff production. The forested site close to the Becher Bach is obviously such a key site - not to determine the average catchment wetness as suggested by Brocca et al. (2007) or Grayson and Western (1998) - but to determine the average wetness of landscape areas that contribute to flood formation.

\subsection{Simulated average soil moisture dynamics}

Based on the model results, we may state that a homogeneous soil setup that uses local observations of $k_{\mathrm{s}}$ and porosity allows at both sites a better model performance as soil profiles that is completely parameterized using the pedo transfer function of Carsel and Parrish (1998). This is no big surprise but underpins on one hand the value of local $k_{\mathrm{S}}$ and porosity observations for setting up physically based models. And it shows on other hand that the residual water content, the air entry value and $n$ parameter estimated based on the 
pedotransfer function of Carsel and Parrish (1998) are sufficient to achieve a good model acceptable performance. This is good news as direct measurement of these parameters is laborious.

At the forested site we found furthermore that a small adjustment of the annual maxima of LAI and plant cover, while assuming that their normalized annual cycles are the same as observed in the Weiherbach catchment (Zehe et al., 2001) leads to a strong improvement of the model bias and RMSE. Simulated averaged soil moisture is almost the whole period within the confidence interval of the observed spatial average soil moisture. We thus may conclude that the best model setup (soil profile A, LAI $=13.5$, plant cover $=0.85$ ) is a promising representation of key areas in the Rehefeld headwater, that could serve as building blocks to represent forested areas in a catchment model. We conclude further that the extend of our sampling grid is large enough to assess the dynamics spatial average soil moisture in almost unbiased way. At the grassland site fine tuning of the model results based on adjusting the annual maxima of root depth, LAI and plant cover was not as successful. We thus may conclude that the normalized annual cycle of grass morphological parameters in Rehefeld must differ from the one in the Weiherbach. We thus conclude that the negative bias the model is not due to non representative sampling but due to insufficient representation of vegetation. A better model performance requires survey of the annual cycles of these plant morphological parameters especially during periods of obviously bad model performance (in early May and in summer).

We overall conclude that the suggested sampling strategy of clustering TDR probes in typical functional units is promising for exploration of soil moisture control on runoff generation, as it yields dynamics of representative soil moisture states at a high temporal resolution. Long term monitoring of such critical landscape elements - the forested site here - may yield valuable information for flood warning. Spatial TDR allows furthermore unraveling different types stochastic and deterministic soil moisture variability within and between soil moisture ensembles. We thus think that STDR provides a good intersect of the advantages of permanent sampling and spatially highly resolved soil moisture sampling using mobile rods. The main drawbacks of STDR are the high cost of a single moisture cluster $(15 \mathrm{k} €)$ as well as the challenge of installing $60 \mathrm{~cm}$ long TDR probes in heterogeneous environments. Monitoring should thus be carefully selected.

Acknowledgements. This study was funded by the German Ministry of Education and Research (BMBF) and is part of the OPAQUE project that aims to improve operational flood forecasting in mountainous headwaters. The authors would like to thank the German Ministry of Education and Research (BMBF) for financial support for the RIMAX project OPAQUE. Furthermore, we thank Dominik Reusser, Bettina Schaefli, Andre Terwei, Peter Eckard, David Kneis, Maik Heistemann, Jenny Eckard, Erik Sommerer and Niko Bornemann for their valuable help during the field season, again Dominik Reusser for valuable comments, two anonymous reviewers for their helpful comments, and Peter Senft for permanent observation of our equipment. We thank furthermore S. Irrgang from "Sachsen Forst" for supporting our field campaign.

Edited by: N. Romano

\section{References}

Albertson, J. D. and Montaldo, N.: Temporal dynamics of soil moisture variability: 1. Theoretical basis, Water Resour. Res., 39(10), W01274, doi:10.1029/2002WR001616, 2003.

Anctil, F., Lauzon, L., and Filion, M.: Added gains of soil moisture content observations for streamflow predictions using neural networks, J. Hydrol., 359(3-4), 225-234, 2008.

Bárdossy, A. and Lehmann, W.: Spatial distribution of soil moisture in a small catchment. Part 1: Geostatistical analysis, J. Hydrol., 206, 1-15, 2001.

Becker, R.: Spatial Time Domain Reflectometry for Monitoring Transient Soil Moisture Profiles. Mitteilungen des Instituts für Wasser und Gewässerentwicklung - Bereich Wasserwirtschaft und Kulturtechnik mit "Theodor-RehbockWasserbaulaboratorium", vol. 228, University of Karlsruhe, Germany, 2004.

Binley, A., Cassiani, G., Middleton, R., and Winship, P.: Vadose zone flow model parameterisation using cross-borehole radar and resistivity imaging, J. Hydrol., 267, 147-159, 2002.

Blöschl, G. and Zehe, E.: On hydrological predictability, Hydrol. Processes, 19(19), 3923-3929, 2005.

Blume T., Zehe, E., Iroume, A., and Bronstert A.: Rainfall runoff response and baseflow separation, Hydrol. Sci. J., 52(5), 843862, 2007.

Blume, T., Zehe, E., and Bronstert, A.: Investigation of runoff generation in a pristine, poorly gauged catchment in the Chilean Andes I: A multi-method experimental study, Hydrol. Processes, 22(18), 3661-3675, doi:10.1002/hyp.6971, 2008a.

Blume, T., Zehe, E., and Bronstert, A.: Investigation of runoff generation in a pristine, poorly gauged catchment in the Chilean Andes II: Qualitative and quantitative use of tracers at three spatial scales, Hydrol. Processes, 22(18), 3676-3688, doi:10.1002/hyp.6970, 2008b.

Blume, T., Zehe, E., and Bronstert, A.: Use of soil moisture dynamics and patterns at different spatio-temporal scales for the investigation of subsurface flow processes, Hydrol. Earth Syst. Sci., 13, 1215-1233, doi:10.5194/hess-13-1215-2009, 2009.

Bronstert, A. and Bárdossy, A.: The role of spatial variability of soil moisture for modelling surface runoff generation at the small catchment scale, Hydrol. Earth Syst. Sci., 3, 505-516, doi:10.5194/hess-3-505-1999, 1999.

Brocca, L., Morbidelli, R., Melone, F., and Moramarco, T.: Soil moisture spatial variability in experimental areas of central Italy, J. Hydrol., 333(2-4), 356-373, 2007.

Brocca, L., Melone, F., Morbidelli, R., and Moramarco, T.: Soil moisture temporal stability over experimental areas in Central Italy, Geoderma, 148(2009) 364-374, doi:10.1016/j.geoderma.2008.11.004, 2009.

Burt, T. P. and Butcher, D. P.: Topographic controls of soil-moisture distributions, Soil Sci., 36(3), 469-486, 1985. 
Chirico, G. B., Grayson, R. B., and Western, A. W.: A downward approach to identifying the structure and parameters of a processbased model for a small experimental catchment, Hydrol Processes, 17(11), 2239-2258, 2003.

Deeks, L. K., Bengough, A. G., Low, D., Billett, M. F., Zhang, X., Crawford, J. W., Chessell, J. M., and Young, I. M.: Spatial variation of effective porosity and its implications for discharge in an upland headwater catchment in Scotland, J. Hydrol., 290, 217-228, 2004.

Dekker, L. W., Oostindie, K., and Ritsema, C. J.: Exponential increase of publications related to water repellency, Aust. J. Soil Res., 43, 403-441, 2005.

Feng, W., Lin, C. P., Deschamps, R. J., and Drnevic, V. P.: Theoretical model of a multisection time domain reflectometry measurement system, Wat. Resources Res., 35(8), 2321-2331, 1999.

Friedman, S. P.: Statistical mixing model for the apparent dielectric constant of unsaturated porous media, Soil Sci. Soc. Am. J., 61(3), 742-745, 1997.

Frisbee, M. D., Allan, C. J., Thomasson, M. J., and Mackereth, R.: Hillslope hydrology and wetland response of two small zeroorder boreal catchments on the Precambrian Shield, Hydrol. Processes, 21, 2979-2997, 2007.

Graeff, T., Zehe, E., Reusser, D., Luck, E., Schroder, B., Wenk, G., John, H., and Bronstert, A.: Process identification through rejection of model structures in a mid-mountainous rural catchment: observations of rainfall-runoff response, geophysical conditions and model inter-comparison, Hydrol. Processes, 23(5), 702-718, doi:10.1002/hyp.7171, 2009.

Graeff, T., Zehe, E., Schlaeger, S., Morgner, M., Bauer, A., Becker, R., Creutzfeldt, B., and Bronstert, A.: A quality assessment of spatial TDR soil moisture measurements in homogenous and heterogeneous media with laboratory experiments, Hydrol. Earth Syst. Sci. Discuss., 7, 269-311, doi:10.5194/hessd-7-269-2010, 2010.

Grayson, R. B., Western, A. W., Chiew, F. H. S., and Blöschl, G.: Preferred states in spatial soil moisture patterns: Local and nonlocal controls, Water Resour. Res., 33, 2897-2908, 1997.

Gurtz, J., Baltensweiler, A., and Lang, H.: Spatially distributed hydrotope-based modelling of evapotranspiration and runoff in mountainous basins, Hydrol Processes, 13(17), 2751-2768, 1999.

Herkelrath, W. N., Hamburg, S. P., and Murphy, F.: Automatic RealTime Monitoring of Soil Moisture in a Remote Field Area with Time Domaine Reflectometry, Water Resour. Res., 27(5), 857864, 1991

Jayawardena, A. W. and Zhou, M. C.: A modified spatial soil moisture storage capacity distribution curve for the Xinanjiang model, J. Hydrol., 227(1-4), 93-113, 2000.

Kemna, A., Vanderborght, J., Kulessa, B., and Vereecken, H.: Imaging and characterisation of subsurface solute transport using electrical resistivity tomography (ERT) and equivalent transport models, J. Hydrol., 267, 125-146, 2002.

Lin, H.: Temporal Stability of Soil Moisture Spatial Pattern and Subsurface Preferential FlowPathways in the Shale Hills Catchment, Vadose Zone J., 5, 317-340, 2006.

Lundstedt, J.: Inverse problems to nonuniform transmission lines, Ph.D. thesis, Royal Institute of Technology, Department of Electromagnetic Theory, Stockholm, 1995.

Lundstedt, J. and He, S.: A time-domain optimization technique for the simultaneous reconstruction of the characteristic impedance, resistance and conductance of a transmission line, J. Electromagn. Waves and Appl., 10(4), 581-602, 1996.

Maurer, T.: Physikalisch begründete, zeitkontinuierliche Modellierung des Wassertransports in kleinen ländlichen Einzugsgebieten. Universität Karlsruhe, Mitteilungen des Instituts für Hydrologie und Wasserwirtschaft, vol. 61, Germany, 1997.

McNamara, J. P., Chandler, D., Seyfried, M., and Achet, S.: Soil moisture states, lateral flow, and streamflow generation in a semiarid, snowmelt-driven catchment, Hydrol Processes, 19, 40234038, 2005.

Merz, B. and Bárdossy, A.: Effects of spatial variability on the rainfall runoff process in a small loess catchment, J. Hydrol., 213(14), 304-317, 1998.

Merz, B., Bárdossy, A., and Schiffler, G. R.: Different methods for modelling the areal infiltration of a grass field under heavy precipitation, Hydrol Processes, 16, 1383-1402, 2002.

Meyles, E., Williams, A., Ternan, L., and Dowd, J.: Runoff generation in relation to soil moisture patterns in a small Dartmoor catchment, Southwest England, Hydrol Processes, 17, 251-264, 2003.

Montgomery, D. R. and Dietrich, W. E.: Runoff generation in a steep, soil-mantled landscape, Water Resour. Res., 38(9), WR000822, doi:10.1029/2001WR000822, 2002.

Nadler, A., Dasberg, S., and Lapid, I.: Time domain reflectometry measurements of water content and electric conductivity of layered soil columns, Soil Sci. Soc. Am. J., 55, 938-943, 1992.

Paasche, H., Tronicke, J., Holliger, K., Green, A. G., and Maurer, H.: Integration of diverse physical-property models: Subsurface zonation and petrophysical parameter estimation based on fuzzy c-means cluster analyses, Geophysics, 71, H33-H44, 2006.

Roth, K. U., Wollschlager, U., Cheng, Z. H., and Zhang, J. B.: Exploring Soil Layers and Water Tables with Ground-Penetrating Radar, Pedosphere, 14, 273-282, 2004.

Schädel, W.: Schritte zur Verbesserung der Hochwasserwarnung mittels Online-Bodenfeuchtemessungen, $\mathrm{PhD}$ thesis, Institute of Water and River Basin Management, Univ. of Karlsruhe, 2006.

Schlaeger, S.: Inversion von TDR-Messungen zur Rekonstruktion räumlich verteilter bodenphysikalischer Parameter, $\mathrm{PhD}$ thesis, 189 pp., Veröffentlichungen des Institutes für Bodenmechanik und Felsmechanik der Universität Fridericiana in Karlsruhe, vol. 156, Karlsruhe, Germany, 2002.

Schlaeger, S.: A fast TDR-inversion technique for the reconstruction of spatial soil moisture content, Hydrol. Earth Syst. Sci., 9, 481-492, doi:10.5194/hess-9-481-2005, 2005.

Starr, J. L. and Timlin, D. J.: TI Using high-resolution soil moisture data to assess soil water dynamics in the vadose zone, Vadose Zone J., 3(3), 926-935, 2005.

Tromp-Van-Meerveld, H. J. and Mcdonnell, J. J.: Threshold relations in subsurface stormflow 1. A storm analysis of the Panola hillslope, Water Resour. Res., 42, W02410, doi:10.1029/2004WR003778, 2006.

Uhlenbrook, S., Frey, M., Leibundgut, C., and Maloszewski, P.: Hydrograph separations in a mesoscale mountainous basin at event and seasonal timescales, Water Resour. Res., 38(6), 1096, 2002.

Western, A. W., Blöschl, G., and Grayson, R. B.: Geostatistical characterisation of soil moisture patterns in the Tarrawarra a catchment, J. Hydrol., 205, 20-37, 1998.

Western, A. W., Zhou, S. L., Grayson, R. B., McMahon, T. A., 
Blöschl, G., and Wilson, D. J.: Spatial correlation of soil moisture in small catchments and its relationship to dominant spatial hydrological processes, J. Hydrol., 286, 113-134, 2004.

Wilson, D. J., Western, A. W., and Grayson, R. B.: Identifying and quantifying sources of variability in temporal and spatial soil moisture observations, Water Resour. Res., 40(2), W2507, doi:10.1029/2003WR002306, 2004.

Zehe, E. and Sivapalan, M.: Threshold behaviour in hydrological systems as (human) geo-ecosystems: manifestations, controls, implications, Hydrol. Earth Syst. Sci., 13, 1273-1297, doi:10.5194/hess-13-1273-2009, 2009.

Zehe, E., Becker, R., Bárdossy, A., and Plate, E.: Uncertainty of simulated catchment sale runoff response in the presence of threshold processes: role of initial soil moisture and precipitation, J. Hydrol., 315(1-4), 183-202, 2005.
Zehe, E. and Blöschl, G. N.: Predictability of hydrologic response at the plot and catchment scales: Role of initial conditions, Water Resour. Res., 40(10), W10202, doi:10.1029/2003WR002869, 2004.

Zehe, E., Elsenbeer, H., Lindenmaier, F., Schulz, K., and Blöschl, G.: Patterns of predictability in hydrological threshold systems, Water Resour. Res., 43, W07434, doi:10.1029/2006WR005589, 2007.

Zehe, E. and Flühler, H.: Slope scale variation of flow patterns in soil profiles, J. Hydrol., 247, 116-132, 2001.

Zimmermann, B, Zehe, E., Hartmann, N. K., and Elsenbeer, H.: Analyzing spatial data: An assessment of assumptions, new methods, and uncertainty using soil hydraulic data, Water Resour. Res., 44, W10408, doi:10.1029/2007WR006604, 2008. 